\title{
Feeding Behavior of the Salamander Gyrinophilus porphyriticus in Caves
}

\author{
by
}

\author{
David C. CULVER*
}

Much of the research done on cave salamanders has concerned the morphological and physiological changes brought about by cave adaptation (Brandon 1971). A great deal of work has been done on eye structure (Brandon 1968), response to light (Hawes 1946, Besharse and Brandon 1973), and metamorphosis (Dent and Kirby-Smith 1963), but the feeding ecology of cave salamanders is poorly understood. From published lists of diets of cave salamanders (Smith 1948, Brandon 1967, Peck 1972), it is clear that they are very generalized predators, and perhaps even omnivores (Lee 1969). Most of the observations on the feeding of salamanders have been lists of gut contents of preserved specimens, and little is known about actual feeding behavior.

In this paper I will discuss feeding behavior and preferences of Gyrinophilus porphyriticus in controlled laboratory experiments. G. porphyriticus occurs in springs and caves throughout much of northeastern United States (Brandon 1966), and most cave populations are small (less than 2 per $100 \mathrm{~m}$ of cave passage) and show little visible sign of cave modification (Cooper and Cooper 1968). In the course of extensive field work in Appalachain caves, Dr. John Holsinger and I have found large populations (more than 5 per $100 \mathrm{~m}$ of cave passage) of $G$. porphyriticus in some caves in the Powell Valley of Virginia and Tennessee. Larvae in these populations are paler and thinner than most larvae of this species and have large, fluffy, pink gills. They are always in streams with large populations of Asellus recurvatus (Isopoda: Asellidae) and/or Crangonyx antennatus (Amphipoda: Gammaridae). The microdistribution and abundance of both $C$. antennatus and $A$. recurvatus were altered by the presence of $G$. porphyriticus, so it seemed likely that G. porphyriticus was feeding on them. Both predators and their potential prey were brought into the laboratory where a series of experiments were done to elucidate method of feeding, prey choice, predator habituation to prey, and response to unfamiliar prey.

\section{METHODS AND MATERIALS}

Four larval G. porphyriticus were collected from the stream in McClures Cave, two from the stream in Cope Cave, and one from a series of cascading rimstone pools in

\footnotetext{
* Department of Biclogical Sciences, Northwestern University, Evanston, Illinois U.S.A. 60201
} 
Sweet Potato Cave. All three caves are in Lee County, Virginia in the Powell River drainage. The larvae were collected in May of 1973. A. recurvatus and $C$. antennatus are present in all three caves. In McClures Cave and Cope Cave, $A$. recurvatus is about 4 to 5 times more abundant than $C$. antennatus. In the gravel-bottomed pools where $G$. porphyriticus is usually found, the prey species are about equally common. The rimstone pool in Sweet Potato Cave where the salamander larva was taken had only $C$. antennatus but nearby rimstone pools had $A$. recurvatus. Sweet Potato Cave and Cope Cave are within the range of the troglobitic isopod Lirceus usdagalun and McClures Cave is near the edge of its range. However, L. usdagalun does not occur in any of the three caves (Holsinger and Bowman 1973). Each larva was kept in a separate aquarium $25 \mathrm{~cm}$ by $10 \mathrm{~cm}$ filled with spring water to a depth of $10 \mathrm{~cm}$. The animals were kept at a temperature of $10^{\circ} \mathrm{C}$ in constant darkness, and the water was changed every week. The $A$. recurvatus, $C$. antennatus and $L$. usdagalun used in the experiments were collected from nearby caves. The substrate of the aquaria was glass, but neither predators nor prey had any trouble moving over it. No mud or rocks were added.

\section{RESULTS}

\section{Mechanics of Predation and Prey Response}

None of the larvae reacted to dead isopods or amphipods, but when a live amphipod or isopod was put in the water, the larvae would raise up on their front legs and usually on their hind legs as well. It then remained motionless until an amphipod or isopod came within 2 to $4 \mathrm{~cm}$ of its snout. Then, with a rapid sucking action sometimes accompanied by a lunge, the salamander ate the prey item. Mechanoreception was the primary method of prey detection and vision seemed to play little or no part in the feeding process. In caves, of course, vision plays no part in feeding. The feeding method of the salamanders was the same in very dim red light and in bright white light. When the amphipod or isopod was near the side of the aquarium, the salamander would often move in the opposite direction the prey organism was moving in attempting to eat the prey. This makes sense if the salamander responds to currents made by the prey, because the patterns of current made by prey movement will change when the prey is near the side of the aquarium. On the other hand, visual cues to prey location are unaffected by the aquarium wall because the lighting was diffuse and overhead. Chemoreception probably plays some role in initiating feeding. After the larva had eaten an amphipod or isopod, it was possible to elicit a feeding response by moving the forceps slowly through the water. However, if forceps were slowly moved through the water before the salamander had eaten anything, no response was elicited. After the salamanders had been in the laboratory for a month, they usually assumed feeding position whenever the cold room door was opened, and would attack forceps before they had eaten anything. In this case, the salamanders had become entrained to associate feeding with the opening of the door.

Feeding success of $G$. porphyriticus varied with the prey involved and depended 
Table 1. Feeding success of Gyrinophilus porphyriticus on Asellus recurvatus and Crangonyx antennatus. Feeding methods are categorized in to two groups: simple sucking in of prey, and sucking in accompanied by lunging at prey. Success drops sharply when the larvae lunise at prey. Frequency of lunging versus not lunging is inflated in favor of lunging because lunging is easier to observe.

Prey Species Feeding Methods No. of Attempts No. of Successes Per Cent Success

Asellus recurvatus

Asellus recurvatus

No lunging

Lunging

Crangonyx antennatus No lunging

Crangonyx antennatus Lunging

12

5

14

7

$\begin{array}{rr}10 & 88 \\ 2 & 40 \\ 7 & 50 \\ 0 & 0\end{array}$

on whether or not the salamander lunged at the prey (Table 1). Success ranged from 0 per cent for $G$. porphyriticus lunging at $C$. antennatus to 88 per cent for $G$. porphyriticus sucking in $A$. recurvatus. The larvae were about twice as successful at sucking in $A$. recurvatus as they were at sucking in $C$. antennatus. Especially striking was the drop in feeding success when the larvae lunged at the prey (Table 1). Lunging behavior appears to be a carry-over from a previous evolutionary stage when the larvae were able to visually locate prey in epigean habitats. Even the related troglobitic species, G. palleucus, with more reduced eyes, can respond to light (Besharse and Brandon 1973). However, since there is no light in caves, behavior associated with visual location of prey is no longer adaptive. This seems to be the case with luriging behavior as well as vision itself.

The isopods (A. recurvatus and L. usdagalun) responded to the salamander by stopping all movernent. This was especially true if there had been a previously unsuccessful attack. As long as they did not move, they were not eaten. In fact, I observed several times a salamander in feeding position ignore an immobile isopod directly underneath its mouth. $C$. antennatus, on the other hand, responded by swimming away. $G$. porphyriticus was unable to move quickly enough to capture swimming $C$. antenratus.

\section{Reaction to Unfamiliar Prey}

Although the range of Lirceus usdagalun encompasses the caves where $G$. porphyriticus was collected, the two never occur together. During the first week in the laboratory, the $7 \mathrm{G}$. porphyriticus larvae sucked in $24 \mathrm{~L}$. usdagalun in the course of predator choice experiments and in the course of general feeding. Seven of these (29 per cent) were actually digested, and the rest were spit out almost immediately after ingestion. At first I thought that Lirceus was toxic, but three salamander larvae that were fed on Lirceus for the next 21 days digested all of the 8 Lirceus that they ingested when retested after 28 to 30 days in the laboratory. What was involved was not learning toxicity (see Brower and Brower 1966), but rather learning edibility. Interestingly, the frequency of Lirceus taken first when given a choice between Lirceus, Asellus, and Crangonyx did not change significantly from the first week to the fifth week. Eight of 34 choices ( 24 per cent) were 
Lirceus during the first week, and 5 of 30 choices (17 per cent) were Lirceus during the fifth week, and the difference was not statistically significant.

\section{Prey Selectivity}

Two experiments were done on selection of prey species-one during the first week and one during the fifth week in the laboratory. In the first experiment, one individual of each prey species was put in the aquarium tank with the salamander larva and checked every 30 minutes for 4 hours. Any prey eaten were replaced. In the second experiment 5 individuals of each prey species were put in the tank and remaining prey were counted every 30 minutes for 6 hours. In spite of the differences in experimental procedures, the frequency of each species taken did not vary significantly between experiments $\left(\chi_{2}^{2}=1.50, \mathrm{P} .<0.90\right)($ Table 2$)$. In both experiments, Asellus recurvatus was the most frequently captured prey item, being taken about 60 per cent of the time (Table 2). There was no evidence that the salamander larvae were actually showing a preference for $A$. recurvatus. Most of the difference in frequency of prey taken is due to differences in feeding success. Since $G$. porphyriticus is more successful in capturing $A$. recurvatus than in capturing $C$. antennatus (Table 1), it was expected that more $A$. recurvatus would be taken when given a choice. I observed no cases in which a larva ignored any of the three prey species when the salamander was nearby. Besides differences in efficiency with which they are captured, prey may also differ in their availability to the salamanders. The isopod species are 'available' when they are moving along the bottom of the aquarium, but not when they are motionless. $C$. antennatus is 'available' when it is moving along the bottom of the aquarium, but not when it is swimming or resting. Although I have no quantitative data on prey availability, my impression is that $A$. recurvatus is more 'available' than $L$. usdagalun or $C$. antennatus. There may be additional differences in the distances over which the larvae detect the different prey species.

\section{Individual Differences in Prey Selection}

There was no indication that any given individual specialized on any particular prey species. Even though $L$. usdagalun does not occur in those caves that larvae were collected from, all seven individuals took at least one Lirceus during prey choice

Table 2. Frequency of different prey species taken by Gyrinophilus porphyriticus larvae when given a choice. Asellus recurvatus is taken most frequently, and this is largely due to a greater feeding success on $A$. recurvatus rather than an actual preference. See text for details of the experimental procedures.

Experiment 1 (first week)

Prey

Asellus recurvatus Crangonyx antennatus Lirceus usdagalun

$$
\text { Number }
$$

Experiment 2 (fifth week)

Number Frequency Frequency 18 0.60 0.59 0.17 0.24
0.23

0.17 
experiments. The only difference in prey availability for the salamanders in the field is that no $A$. recurvatus were in the pool where the larva from Sweet Potato Cave was taken. A. recurvatus may have been present in the pool previously and had been eaten by the salamander, but in any case there was no indication that the Sweet Potato larva preferred $C$. antennatus in the laboratory. In the first week of experiments on prey choice where differences in feeding history are most likely to be expressed, 20 per cent of the five prey taken by the Sweet Potato Cave larva were $C$. antennatus, and 17 per cent of the 29 prey taken by the other larvae were C. antennatus. The difference was not statistically significant. None of the larvae took more than 40 per cent $C$. antennatus, 35 per cent $L$. usdagalun, or less than 50 per cent $A$. recurvatus, and so the range of individual variation was rather restricted.

\section{The Effect of Habituation to Prey}

Two salamanders, one crom Cope Cave and one from McClure Cave were given only A. recurvatus for a period of two weeks. Three individuals, two from McClure Cave and one from Sweet Potato Cave, were given only $C$. antennatus for a period of two weeks. Choice experiments were done before and after habituation to the prey. For those given only $C$. antennatus there was no increase in the proportion of $C$. antennatus taken after habituation (Table 3 ). For those given only $A$. recurvatus, the frequency of $C$. antennatus taken decreased to zero after habituation (Table 3 ), a statistically significant difference (Fisher's exact test, $\mathrm{P}>0.99$ ). This was the only case of a shift or difference in diet found in this study. The larvae habituated to $A$. recurvatus occasionally tried to capture $C$. antennatus, but were unsuccessful. The frequency of attempts to capture $C$. antennatus may have dropped as well, but there are no data to support this.

\section{Size Selection}

Six salamanders were each presented a succession of choices between two sizes of $A$. recurvatus. Two $A$. recurvatus between 4 and $7 \mathrm{~mm}$ long and two $A$. recurvatus, between 11 and $14 \mathrm{~mm}$ long were placed in the aquarium with a salamander larva, and the number and type eaten was checked every 30 minutes for 4 hours. All isopods eaten were replaced. Except for the smallest larva, which had a snout-vent

Table 3. Effect of habituation to prey on prey selection by Gyrinophilus porphyriticus larvae. Only larvae habituated to Asellus recurvatus showed any change in frequency of prey taken.

Condition

No. C. antennatus taken

No. A. recurvatus taken

$\%$ C. antennatus

Before habituation to $C$. antennatus After habituation to $C$. antennatus Before habituation to $A$. recurvatus After habituation to $A$. recurvatus

10

3

5

0
20

12

16

11 
Table 4. Size selection by Gyrinophilus porphyriticus larvae of Asellus recurvatus. Two size groups of $A$. recurvatus were used: one between 4 and $7 \mathrm{~mm}$ and the other between 11 and $14 \mathrm{~mm}$. Only the smallest larva showed significant size selection.

$\begin{array}{lccc}\text { Cave } & \text { Snout-Vent Length } & \text { No. of small isopods taken } & \text { Freq. of small iso } \\ \text { Sweet Potato } & 60 & 2 & 0.40 \\ \text { McClure } & 65 & 2 & 0.33 \\ \text { Cope } & 70 & 1 & 0.33 \\ \text { McClure } & 70 & 4 & 0.80 \\ \text { Cope } & 75 & 1 & 0.50 \\ \text { TOTAL } & - & 10 & 0.48 \\ \text { McClure } & 45 & 4 & 1.00\end{array}$

length of $45 \mathrm{~mm}$, the five salamanders with snout-vent lengths ranging from 60 to $75 \mathrm{~mm}$ showed no tendency to choose a particular size group (Table 4). These five salamanders ate a total of 21 isopods, 10 of which were small. Thus, it was only the small larva that showed any preference, and it tended to eat small isopods. Still smaller salamanders probably feed on copepods and ostracods rather than amphipods and isopods.

\section{DISCUSSION AND CONCLUSIONS}

Gyrinophilus porphyriticus is generally assumed to show little sign of adaptation to cave life (Brandon 1971, Cooper and Cooper 1968). However, data obtained in the present study indicate that some cave populations of the species do share characteristics with cave-limited species. First, both cave-limited species and the individuals of $G$. porphyriticus studied raise up on their legs to detect prey. This allows for more efficient operation of the lateral-line system. Second, available data indicate that feeding success of $G$. porphyriticus is roughly comparable to that of one cave-limited species-Haideotriton wallacei. On the basis of the presence or absence of crustaceans in food boluses in the guts, Peck (1973) found that $H$. wallace $i$ was successful in obtaining food about 67 per cent of the time. The success rate of $G$. porphyriticus in the laboratory, when it did not lunge at prey, was slightly greater than the success rate in the field of $H$. wallacei when $G$. porphyriticus was eating $A$. recurvatus, and slightly less when it was eating $C$. antennatus. Third, $G$. porphyriticus feeds on all the available macroscopic species in the caves (see Culver 1973), and thus is a generalized predator, as are the cave-limited forms. The high frequency of $A$. recurvatus taken in choice experiments results from a high rate of feeding success rather than a preference for A. recurvatus. Finally, the ability to 'learn' to eat unfamiliar prey such as Lirceus usdagalun would seem to be adaptive in an environment where food is often scarce, and would enable the salamander larvae to utilize organisms washed into the cave.

On the other hand, the individuals of $G$. porphyriticus studied showed signs of an evolutionary history in epigean environments. The most striking example of this 
was the lunging behavior larvae occasionally showed when attempting to capture prey. This behavior would be adaptive for an animal that visually located and detected prey, but it does not seem to be adaptive for larvae in caves (see Table 1). Other cave populations of $G$. porphyriticus show more strongly pronounced epigean traits. Most $G$. porphyriticus larvae found in West Virginia caves are more sluggish, fatter, don't raise up on their legs to detect prey, and feed on earthworms that are in or at the edge of the water (Culver, unpublished). Brandon's (1971) comment that larval feeding history has a large effect on feeding behavior can probably be extended to some morphological and physiological differences as well. For example, most of the adult salamanders seen in Cope Cave, McClure Cave, and Sweet Potato Cave were in the stream, while most of the adults seen in West Virginia caves were out of the water. It is not known whether these differences are primarily due to genetic differences or whether they are due to environmental differences between the caves that may affect growth and development of the larvae. Further work on this question should provide considerable insight into the dynamics of initial stages of adaptation to caves.

Since salamanders are usually not common enough in caves so that an ecologist can take more than four or five individuals without damaging the population, there are two things he or she can do: either make a detailed examination of food boluses in the gut (Peck 1973), or do feeding experiments in the laboratory (the present study). Both kinds of data are useful. Since many salamanders, both in and out of caves, have very broad diets, it is important that the variety and relative abundance of prey available be assessed (see Martof and Scott 1957). A great deal of information can be obtained in laboratory studies on predation that shed light on not only the mechanism of predation but also its effects on prey populations (see Emlen 1973). But it is often difficult to obtain enough natural prey to do many experiments. The ecological role and the evolutionary adaptations of cave salamanders will not be understood until both approaches are utilized for other species of cave salamanders.

\section{ACKNOWLEDGEMENTS}

Research was supported by a grant from the Office of Research and Sponsored Projects of Northwestern University. Naomi Culver, John Holsinger, Thomas Kane, and James Keith helped with the field work. Drs. John Holsinger and Thomas Poulson offered many helpful comments.

\section{SUMMARY}

The feeding responses of salamander larvae (Gyrinophilus porphyriticus) from caves in the Powell Valley in Virginia were investigated in the laboratory. The larvae locate prey by mechanoreception and capture the prey by a rapid sucking action, much like cave-limited salamanders do. Feeding success is greater with the isopod 
Asellus recurvatus (about 90 per cent) than with the amphipod Crangonyx antennatus (about 50 per cent), and this largely accounts for the higher frequency of $A$. recurvatus taken in choice experiments. G. porphyriticus readily ingested the unfamiliar isopod Lirceus usdagalun, but it took four weeks before it was digested as well. Small larvae tend to take small prey and large larvae take both large and small prey. Occasionally, larvae lunged at prey, which was usually unsuccessful. This behavior seems to be a holdover from an evolutionary history in epigean environments where vision could be used to locate prey.

\section{RESUME}

Le comportement alimentaire de larves de salamandre (Gyrinophilus porphyriticus) provenant des grottes de la Powell Valley (Virginie) a été étudié au laboratoire. Les larves localisent la proie grâce à une perception de type mécanique et la capturent d'un rapide mouvement de succion, à la manière des salamandres cavernicoles. La prédation réussit plus avec l'Isopode Asellus recurvatus (environ 90\%) qu'avec l'Amphipode Crangonyx antennatus (environ 50\%); ceci rend compte, dans une large mesure, de la plus grande fréquence présentée par $A$. recurvatus lors de expériences faites sur la préférence alimentaire. G. porphyriticus a volontiers ingéré Lirceus usdagalun, Isopode qui lui était inconnu, mais il a fallu attendre quatre semaines pour qu'il soit également bien digéré. Les petites larves ont tendance à capturer de petites proies, les grandes larves en prennent des petites comme des grosses. Parfois les larves portent un coup à une proie qui habituellement n'a pas de succès. Ce comportement semble être la survivance d'une évolution en milieu épigé, où la vue a pu servir à localiser la proie.

\section{REFERENCES}

BESHARSE, J.C. and R.A. BRANDON, 1973: Optomotor response and eye structure of the troglobitic salamander, Gyrinophilus palleucus. Amer. Midland Natur. 89: 463-467.

BRANDON, R.A. 1966: Systematics of the salamander genus Gyrinophilus. Illinois Biol. Monogr. 35: 1-86.

BRANDON, R.A. 1967: Food and a intestinal parasite of the troglobitic salamander Gyrinophilus palleucus necturoides. Herpetologica 23: 52-53.

BRANDON, R.A. 1968: Structure of the eye of Haideotriton wallacei, a North American troglobitic salamander. J. Morphol. 124: 345-351.

BRANDON, R.A. 1971: North American troglobitic salamanders: some aspects of modification in cave habitats, with special reference of Gyrinophilus palleucus. Nat. Speleol. Soc., Bull. 33: 1-22.

BROWER, J.V.Z. and L.P. BROWER, 1966: Experimental evidence of the effects of mimicry. Amer. Natur. 100: 173-187.

COOPER, J.E. and COOPER, M.R. 1968: Cave-associated herpetozoa II. Salamanders of the genus Gyrinophilus in Alabama caves. Nat. Speleol. Soc., Bull. 30: 19-24.

CULVER, D.C. 1973: Competition in spatially heterogeneous systems: an analysis of simple cave communities. Ecology 54: 102-110.

DENT, J.N. and KIRBY-SMITH, J.S. 1963: Metamorphic physiology and morphology of the cave salamander Gyrinophilus palleucus. Copeia (1963): 119-130. 
EMLEN, J.M. 1973: Ecology: an evolutionary approach. Addison-Wesley, Reading, Mass. 493 p.

HAWES, R.S. 1946: On the eyes and reactions to light of Proteus anguinus. Quart. J. Microsc. Sci. $86: 1-53$.

HOLSINGER, J.R. and BOWMAN, T.E. 1973: A new troglobitic isopod of the genus Lirceus (Asellidae) from southwestern Virginia, with notes on its ecology and additional cave records for the genus in the Appalachians. Int. J. Speleol. 5: 261-272.

LEE, D.S. 1969: A food study of the salamander Haideotriton wallacei Carr. Herpetologica 4: 205-208.

MARTOF, B.S. and SCOTT, D.C. 1957: The food of the salamander Leurognathus. Ecology 38: 494-501.

PECK, S.B. 1973: Feeding efficiency in the cave salamander Haideotriton wallacei. Int. J. Speleol. 5: 15-19.

SMITH, P.W. 1948: Food habits of cave dwelling amphibians. Herpetologica 4: 205-208. 